\title{
Subacute Neurological Deterioration with Selective Axonal Injury in Patients with Acute Ischemic Stroke following Reperfusion of Middle Cerebral Artery Occlusion
}

\author{
Yang-Ha Hwang ${ }^{a, c}$ Yong-Won Kim ${ }^{a, c}$ Jongyeol Kim ${ }^{d}$ \\ Yong-Sun Kim ${ }^{b, c}$ Sung-Pa Park ${ }^{a}$ Chung-Kyu Suha, c \\ Departments of a Neurology, ${ }^{\mathrm{b}}$ Neuroradiology, and 'Daegu-Gyeongbuk Cardio-Cerebrovascular \\ Center, Kyungpook National University Hospital, Daegu, Republic of Korea; ${ }^{\mathrm{d}}$ Texas Tech \\ University Health Sciences Center, Lubbock, Tex., USA
}

\section{Key Words}

Reperfusion · Acute ischemic stroke $\cdot$ Neurological deterioration

\begin{abstract}
To date, the long-term effects of reperfusion on the salvaged brain tissues have not been addressed in the literature. We report 4 cases presenting subacute neurological deteriorations with selective axonal injury following reperfusion therapies for acute ischemic stroke. Our case series based on 4 patients showed common features distinct from those of early reperfusion injury in that (1) the neurological symptoms developed after 1-2 months of reperfusion therapies, (2) these symptoms were accompanied by the subcortical white matter changes on brain MRI, and (3) these findings were mostly reversible with time. This suggests that axons in the reperfused brain may be vulnerable to further neurological injury.
\end{abstract}

\section{Introduction}

Reopening of occluded vessels in patients with acute ischemic stroke has been one of the therapeutic options, which improves clinical outcome through regional reperfusion and salvage of threatened brain tissues [1]. Reperfusion, however, sometimes carries certain risks known as 'cerebral reperfusion injury' including no reflow phenomenon, postischemic hyperperfusion, or brain hemorrhage and edema associated with the breakdown of the blood-brain barrier, which mostly occur within 1 week after 
reperfusion $[2,3]$. We herein report 4 cases that showed subacute neurological deterioration combined with newly developed brain white matter (WM) lesions presumably associated with selective axonal injury following reperfusion of occluded vessels after 1-2 months of index stroke.

\section{Case Report}

\section{Illustrative Case (Case 1)}

A 68-year-old, right-handed woman was admitted with gradual onset of speech disturbance. About 50 days prior to admission, she underwent intra-arterial reperfusion therapy for acute ischemic stroke due to left middle cerebral artery occlusion. With successful recanalization, her global aphasia and right arm weakness rapidly improved, and she regained excellent functional recovery with subtle right arm weakness. Two weeks before admission, she developed progressive onset of speech disturbance - she was not able to form words. Neurological examination showed expressive aphasia without any weakness of extremities. The brain MRI revealed increased signal intensities of the left subcortical WMs on T2WI, FLAIR, and DWI without any concomitant vascular occlusion of the corresponding artery. During hospitalization, she showed some improvement in spontaneous speech. One month after discharge, she recovered to her previous functional status with nearly complete resolution of speech disturbance. Follow-up brain MRI about 3 months following the second admission, showed decreased signal intensities of the left subcortical WMs on the same MRI sequences (fig. 1). Details of the 4 cases are summarized in table 1.

\section{Discussion}

To our knowledge, this is the first case report addressing the chronic effects of reperfusion, the so-called 'delayed selective axonal injury in reperfused brain', in cases with acute ischemic stroke due to middle cerebral artery occlusion. Moreover, neurological adverse events related to reperfusion in human ischemic stroke were reported within several days from onset $[4,5]$. This type of reperfusion injury was expressed as brain hemorrhage or secondary ischemia associated with disruption of the blood-brain barrier, no reflow phenomenon, and postischemic hyperperfusion $[2,3,6]$. Our case series, however, have some common features distinct from those of early reperfusion injury in that (1) the neurological symptoms appeared after 1-2 months of reperfusion therapies, (2) these symptoms were accompanied by the subcortical WM changes on brain MRI, and (3) these findings were mostly reversible with time.

Microscopic cellular damage can occur in the reperfused brain. In general, neurons are more vulnerable than glial cells or blood vessels, and oligodendroglia are more vulnerable than astrocytes and microglia in the global ischemia model [7]. Our proposed explanation for delayed selective axonal injury in reperfused brain was as follows: during the first hours of focal ischemia, the neurons are more vulnerable to ischemia than axonal structures, so ischemia resistant axons have greater chance to survive with reperfusion. However, some survived axons can be damaged in the microenvironmental levels, and after passing the silent period, clinical deterioration and subcortical WM lesions may occur in some cases. Our findings may suggest that the reperfused brain may be susceptible after acute stages of ischemic stroke. Accordingly, long-term follow-up imaging might be needed to elucidate the real frequency and clinical features in the consecutive thrombolysis registry. 


\section{Disclosure Statement}

The authors of the present study have no financial, personal, or professional relationships with other people or organizations that could reasonably be perceived as conflicts of interest or as potentially influencing or biasing their work.

Table 1. Summary of clinical and angiographic characteristics of 4 cases

\begin{tabular}{|c|c|c|c|c|}
\hline Case No. & Case 1 & Case 2 & Case 3 & Case 4 \\
\hline Sex/Age & $\mathrm{F} / 68$ & $\mathrm{M} / 73$ & $\mathrm{~F} / 77$ & $\mathrm{M} / 70$ \\
\hline Initial NIHSS score & 12 & 19 & 10 & 10 \\
\hline Clinical presentation & $\begin{array}{l}\text { Global aphasia with right } \\
\text { arm weakness }\end{array}$ & $\begin{array}{l}\text { Global aphasia with right } \\
\text { hemiparesis }\end{array}$ & $\begin{array}{l}\text { Global aphasia with right } \\
\text { hemiparesis }\end{array}$ & $\begin{array}{l}\text { Global aphasia with right } \\
\text { hemiparesis }\end{array}$ \\
\hline Onset-to-door time, $\min$ & 350 & 210 & 78 & 660 \\
\hline Site of vascular occlusion & $\begin{array}{l}\text { Left M1 distal superior } \\
\text { branch occlusion }\end{array}$ & $\begin{array}{l}\text { Left M1 distal inferior } \\
\text { branch occlusion }\end{array}$ & Left M1 distal stem occlusion & $\begin{array}{l}\text { Left M1 distal stem } \\
\text { occlusion }\end{array}$ \\
\hline Method of reperfusion & Mechanical clot disruption & Mechanical clot disruption & IV rtPA $(0.6$ mg/kg) & Anticoagulation \\
\hline Immediate reperfusion & Yes & No & Yes & No \\
\hline 7-day NIHSS score & 2 & 11 & 1 & 5 \\
\hline Neurological deterioration & Progressive motor aphasia & Progressive aphasia & $\begin{array}{l}\text { New onset headache, memory } \\
\text { impairment }\end{array}$ & $\begin{array}{l}\text { Progressive aphasia, } \\
\text { cognitive impairment }\end{array}$ \\
\hline Approximate time since ictus & 1 month & 2 months & 2 months & 1 month \\
\hline Risk factors & Hyperlipidemia & $\begin{array}{l}\text { Hypertension, atrial } \\
\text { fibrillation }\end{array}$ & $\begin{array}{l}\text { Hyperlipidemia, atrial } \\
\text { fibrillation }\end{array}$ & $\begin{array}{l}\text { Hypertension, diabetes, } \\
\text { hyperlipidemia }\end{array}$ \\
\hline
\end{tabular}

NIHSS = National Institutes of Health Stroke Scale. 

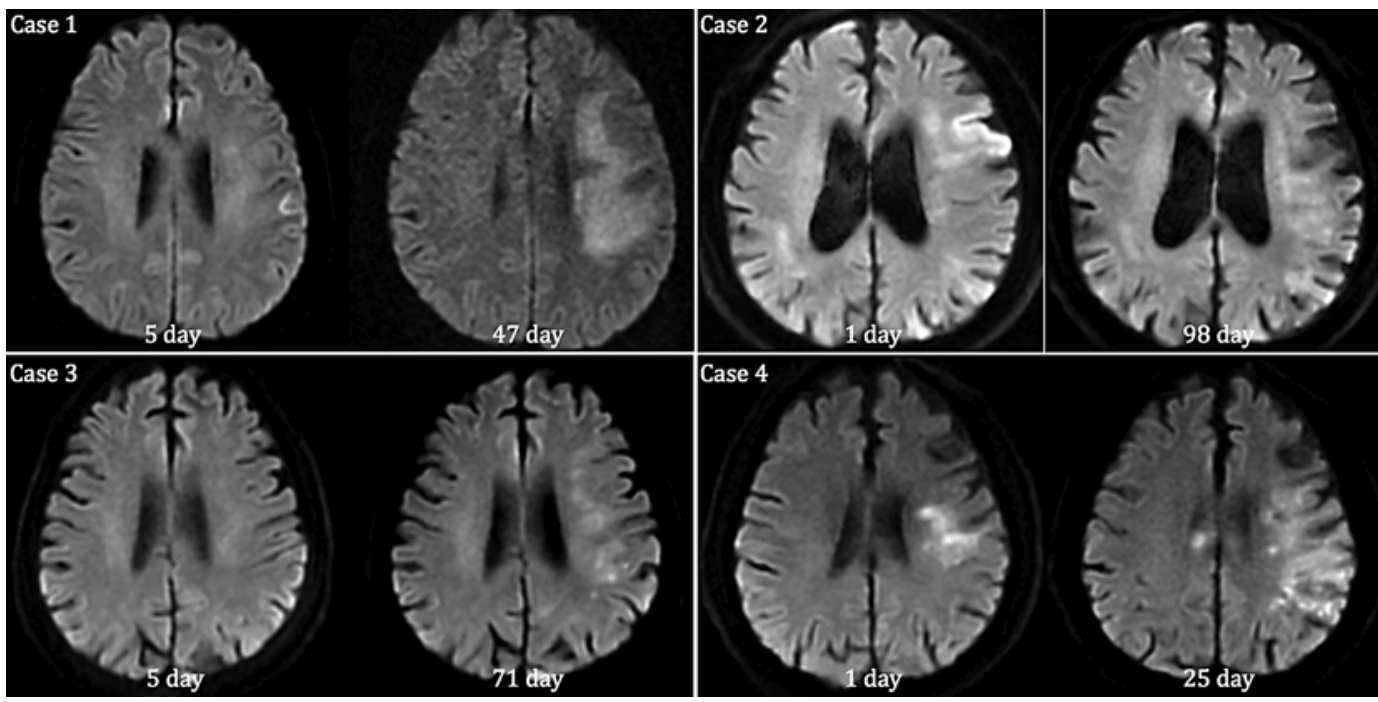

Fig. 1. Sequential changes of DWI (cases 1-4). The baseline DWI (left side of each figure) shows scanty WM hyperintensities with clinical improvement during the acute stage of ischemic stroke. With progressive neurological deterioration, the follow-up DWI (right side of each figure) shows widespread WM hyperintensities unrelated with index stroke.

\section{References}

$\checkmark 1$ Rha JH, JL Saver: The impact of recanalization on ischemic stroke outcome: a meta-analysis. Stroke 2007;38:967-973.

-2 Pan J, Konstas AA, Bateman B, Ortolano GA, Pile-Spellman J: Reperfusion injury following cerebral ischemia: pathophysiology, MR imaging, and potential therapies. Neuroradiology 2007;49:93-102.

3 Schaller B, Graf R: Cerebral ischemia and reperfusion: the pathophysiologic concept as a basis for clinical therapy. J Cereb Blood Flow Metab 2004;24:351-371.

-4 Kidwell CS, Saver JL, Mattiello J, Starkman S, Vinuela F, Duckwiler G, Gobin YP, Jahan R, Vespa P, Villablanca JP, Liebeskind DS, Woods RP, Alger JR: Diffusion-perfusion MRI characterization of post-recanalization hyperperfusion in humans. Neurology 2001;57:2015-2021.

5 Kidwell CS, Saver JL, Starkman S, Duckwiler G, Jahan R, Vespa P, Villablanca JP, Liebeskind DS, Gobin YP, Vinuela F, Alger JR: Late secondary ischemic injury in patients receiving intraarterial thrombolysis. Ann Neurol 2002;52:698-703.

-6 White BC, Sullivan JM, DeGracia DJ, O’Neil BJ, Neumar RW, Grossman LI, Rafols JA, Krause GS: Brain ischemia and reperfusion: molecular mechanisms of neuronal injury. J Neurol Sci 2000;179:1-33.

7 Garcia JH, Lassen NA, Weiller C, Sperling B, Nakagawara J: Ischemic stroke and incomplete infarction. Stroke 1996;27:761-765. 